Retraction

\title{
Retracted: Difference between Mechanical Alignment in Navigation and Scanogram during Total Knee Arthroplasty
}

\section{Advances in Orthopedics}

Received 20 May 2020; Accepted 21 May 2020; Published 16 July 2020

Copyright $\odot 2020$ Advances in Orthopedics. This is an open access article distributed under the Creative Commons Attribution License, which permits unrestricted use, distribution, and reproduction in any medium, provided the original work is properly cited.

At the request of the authors, the article titled "Difference between Mechanical Alignment in Navigation and Scanogram during Total Knee Arthroplasty" [1] is being retracted.

During discussion among the authors following publication, it was found that one of the authors had mistakenly entered data into an incorrect location in a spreadsheet. The dataset cannot be corrected because it is not possible to identify which data entries are incorrect, and therefore, the article is being retracted at the request of the authors due to these concerns.

\section{References}

[1] R. Bhimani, F. Bhimani, and P. Singh, "Difference between Mechanical Alignment in Navigation and Scanogram during Total Knee Arthroplasty," Advances in Orthopedics, vol. 2019, Article ID 4096306, 5 pages, 2019. 